\title{
Ödül ve Bedel Bölüşümüne İlişkin Haklılık Algılarında Katkı Türü ve İç-Grup Üyeliğinin Etkisi
}

\author{
Suzan Ceylan-Batur \\ TOBB Ekonomi ve Teknoloji Üniversitesi
}

\begin{abstract}
Özet
Bu araştırma ödül ve bedel bölüşümüne ilişkin haklılık algılarında katkı türü ve iç-grup üyeliğinin etkisini incelemek amacıyla yürütülmüştür. Çalışmada veri toplama aracı olarak yetenek/çaba, ödül/bedel, iç-grup/dış-grup değişkenlerinin değişimlenmeleriyle oluşturulan deneysel koşulları temsil eden sekiz öykü kullanılmıştır. Öykülerde, yarışmaya katılmak üzere ortak proje yürüten iki kişiden biri iç-grup, diğeri dış-grup üyesi olup, yeteneği ya da çabasıyla sonuca daha az ya da daha fazla katkıda bulunmaktadır.

Bu çalışmada üniversite öğrencisi 160 katılımcıya, başarı koşulunda ödülü, başarısızlık koşulunda bedeli nasıl paylaştıracakları sorulmuştur. Ayrıca kendilerine sunulan eşit derecede ödül ya da bedel paylaştırma önerisini ne ölçüde adil bulduklarını değerlendirmeleri istenmiştir. Analiz sonuçları, çaba söz konusu olduğunda ödül ve bedelin iç-grup dış-grup ayrımı yapılmadan katkıya göre dağıtıldığını göstermiştir. Yetenek söz konusu olduğunda ise bedelin her iki gruba da eşit dağıtıldığı gözlenmiştir. Ancak katılımcılar, daha çok yetenekli olan iç-grup üyesi olduğunda ödülün katkıya göre, dış-grup üyesi olduğunda ise eşit dağıtılmasını tercih etmişlerdir. Katılımcılar, eşit pay dağıtımını, bedelin söz konusu olduğu durumda ödüle; yetenek söz konusu olduğunda çabaya; daha çok katkı gösteren diş-grup üyesi olduğunda iç-grup üyesine kıyasla daha adil algılamışlardır.
\end{abstract}

Anahtar kelimeler: Bölüşümsel adalet, kaynak dağıtımı, ödül-bedel haklılığ1, eşitlik, hakçalık, iç-grup yanlılığ1

\begin{abstract}
The present study was designed to examine the effect of effort/ability based contributions and in-group membership on the perceived fairness of positive and negative outcomes. Participants read a vignette about two target persons (one of them being an in-group member and the other an out-group member) working on a joint project. These co-workers' inputs were manipulated in such a way that one of them contributed more with either a higher ability or more effort to the accomplishment of the project. Their outputs were also manipulated to have either positive (reward) or negative (cost) outcomes.

Participants (160 university students) were asked to allocate reward in positive condition and cost in negative condition among co-workers in the vignette. Then, they were asked to rate the degree of fairness of the distribution of equal outcomes. The results revealed that when the contribution type is effort, participants allocated both the rewards and the costs according to equity norm. When the contribution type is ability, participants allocated costs equally. However, when the target person who contributed more with a higher ability is in-group member, the reward is distributed proportionally; while the person is out-group member, the reward is equally distributed. The equal distribution is judged to be fairer by the participants when the contribution type is ability rather than effort; when the outcome is cost rather than reward; and when the person who contributed more is out-group member rather than in-group member.
\end{abstract}

Keywords: Distributive justice, resource allocation, outcome fairness, equality, equity, in-group bias

Yazışma Adresi: Dr. Öğr. Üyesi Suzan Ceylan-Batur, TOBB Ekonomi ve Teknoloji Üniversitesi, Fen Edebiyat Fakültesi, Psikoloji Bölümü, Söğ̈̈̈tözü Caddesi No:43, Söğütözü, 06560 Ankara.

E-posta: scbatur@etu.edu.tr

Gönderim Tarihi: 19.03.2018

Kabul Tarihi: 14.03.2019 
Ödüllerin bölüşülmesi ve bedellerin ödenmesi sürecinde bireylerin paylarına düşeni ne derecede adil olarak değerlendirdiklerinin ve bu değerlendirmede rol oynayan ilke ve etkenlerin belirlenmesi uzun yillardan beri sosyal psikologların ilgisini çeken konulardan biri olmuştur (Akgün, 2004; Deutsch, 1975, 1985; Lamm ve Schwinger, 1980; Sabbagh ve Schmitt, 1998; Scott, Matland, Michelbach ve Bornstein, 2001; Şahin, 2006). Sosyal psikolojide bu konuyla ilgili çalışmalar bölüşümsel adalet başlığı altında sürdürülmektedir. Bu konuda çalışan ilk araştırmacıların ödül ve bedellerin dağıtımına ilişkin adillik algılarının temelinde aynı süreçlerin yattığ ilişkin varsayımlarına (Kayser ve Lamm, 1980; Lamm ve Kayser, 1978) karşın, daha sonraki yıllarda bazı araştırmacılar ödül ile bedel dağıtımına ilişkin adillik algılarının temelinde farklı süreçlerin yatabileceğini öne sürmüşlerdir (Sabbagh ve Schmitt, 1998; Törnblom ve Ahlin, 1998). Doğrudan doğruya ya da dolaylı olarak bu iki farklı görüşün sınandığı araştırmalardan bu konuda kesin bir yargıya varmaya olanak tanıyacak ölçüde tutarlı sonuçlar elde edilmemiștir (Kayser ve Lamm, 1980; Lamm ve Kayser, 1978; Lamm, Kayser ve Schanz, 1983; Şahin, 2003). Bunun yanı sıra, bireylerin bedel dağıtımı yaparken de iç grup yanlılı̆̆ gösterip göstermedikleri ve çaba ya da yeteneği nedeniyle olumlu ya da olumsuz bir sonuca daha fazla katkıda bulunan kișinin iç-grup ya da dış-grup üyesi olmasının pay dağılımına ilişkin tercihlerde bir değişmeye yol açıp açmadığı gibi soruların yanıtlarında tutarsızlıklar görülmüştür (örn., Mummendey ve ark., 1992; Otten ve Mummendey, 1999; Şahin, 2003).

Dolayısıyla, pay dağıtımına ilişkin adillik algılarının temelinde yatan süreçler konusunda daha fazla araştırmaya gereksinim vardır. Bu çalışmada temel olarak, pay dağıtımının adil olarak algılanıp algılanmamasında rol oynayan etmenlerin incelenmesi amaçlanmıştır. $\mathrm{Bu}$ kapsamda pay dağııım ilkesi (hakçalık, eşitlik), payın niteliği (ödül, bedel), katk1 türünün niteliği (çaba, yetenek) ve pay dağıtılan kişinin grup üyeliği (iç grup, dış grup) ele alınmaktadır.

\section{Pay dağıtım ilkeleri}

Bölüşümsel adalet başlığı altında yürütülen çalıșmalar, kaynak dağıtımında farklı ilkelerin kullanıldı̆̆ını; insanların ödül ve bedellerin paylaştırılması sürecinde hakçalık, eşitlik ve gereksinim ilkesi olarak adlandırılan üç ilkeden yaralandıklarını ortaya koymuştur (Deutsch, 1975; Leventhal, 1976). Bu çalışma kapsamında hakçalık ve eşitlik ilkeleri ele alınmaktadır (Gereksinim ilkesi için bkz. Murphy-Berman ve Berman, 2002; Şahin, 2006).

Hakçalık İlkesi. Hakçalık ilkesi herkesin katkısına göre pay almasını ya da sorumluluğuna göre bedel ödemesini öngörür. Bir başka deyişle katkısı çok olan birey, daha az katkıda bulunana kıyasla ödülden çok almalı, bedeli daha az ödemelidir. Bu alanda yapılan ilk çalışmalarda (Adams, 1965; Homans, 1961) bireylerin kaynak dağıtımında hakçalık ilkesine göre hareket ettiğini destekleyen sonuçlar alınmış̧ır. Araştırma bulguları genel olarak kişilerin hakça dağıtımı adil bulduklarını, dağıtımın hakça yapılmadığı durumlarda bu durumu adil bulmayıp kaynağın yeniden dağıtılması yoluna gittiklerini göstermiştir.

Eşitlik İlkesi. Bölüşümsel adalet konusunda yapılan çalışmalar zamanla hakçalık ilkesinin adil kaynak dağıtımında tek ilke olmadığını, farklı adalet ilkelerinin de bu süreçte rol oynayabildiğini göstermiştir (Deutsch, 1985). Bu dönemde öne sürülen ilkelerden biri eşitlik ilkesidir. Eşitlik ilkesi ödül ve bedellerin eşit şekilde dağıtılmasını öngörür. Bu ilkeye göre tüm paylaşımlar, bireylerin katkısından bağımsız olarak, eşit olmalıdır (Leventhal, 1976; Schwinger, 1986).

\section{Payın Niteliği - Ödüi/Bedel}

Pay dağıtımının adil olarak algılanıp algılanmamasında rol oynayan bir diğer etmen payın niteliğidir. Bölüşümsel adalet konusunda yapılan ilk çalışmalarda daha çok ödüllerin dağıtımına ilişkin adillik algıları incelenmiş, ödül ve bedellerin dağıtımına ilişkin algıların temelinde aynı süreçlerin yattığı varsayımı ile bedel paylaşımı üzerinde fazla durulmamıştır. Deutsch (1975), Lerner $(1974 ; 1975 ; 1977)$ ve Leventhal (1976) ödül dağıtımındaki adalet anlayışında, eşitlik ve hakçalık ilkelerinden söz ederken, olumlu ve olumsuz sonuçları birlikte kullanmış, dolayısıyla yazarlar görüşlerini iletirken çoklu adalet ilkelerinin her iki durum için de aynı şekilde işlediğini varsaymışlardır. Ancak daha sonraki yıllarda ödül ile bedel dağıtımına ilişkin adillik algılarının temelinde farklı süreçlerin yatabileceği yolunda görüşler öne sürülmeye başlanmıştır (Sabbagh ve Schmitt, 1998; Törnblom ve Ahlin, 1998).

Bu konuda yapılan çalışmaların birçoğunda, olumlu sonuç durumunda kişilerin hakçalık ilkesini eşitlik ilkesine göre daha adil bulduğu, olumsuz sonuç durumunda ise eşitlik ilkesinin tercih edildiği söylenmektedir (Brickman, Folger, Goode ve Schul, 1981; Elster, 1989; Goodwin, 1992; Kayser ve Lamm, 1980; Törnblom ve Jonsson, 1985). Törnblom, Mühlhausen ve Jonnson'ın (1991) olumlu ve olumsuz sonuçların dağıtımında aynı ya da farklı adalet ilkelerinin hangi koşullar altında ve ne derece geçerli olduğu sorusuna yanıt aramak için yaptıkları araştırmada, katılımcılar, sonuçtan sorumlu olmayan kişilerin, sorumlu olanı bildikleri koşulda, ödül ve bedel dağıtımının her ikisinin de eşit yapılmasının daha adil olduğunu düşüneceklerini belirtmişlerdir. Diğer durumda, yani sonuçtan sorumlu olanın bilinmediği koşulda ise, katılımcılar, ödülün eşit dağııılmasının adil bulunacağını 
ancak bedelin eşit dağıtılmasının adil bulunmayacağını belirtmişlerdir. Yani olumlu sonuçlar söz konusu olduğunda genel olarak eşitlik ilkesi adil bulunurken olumsuz sonuçlarda eşit pay dağıtımı koşulsuz olarak adil algılanmamaktadır.

\section{Pay dağıtımında katkı türünün niteliği - Çaba/Yetenek}

$\mathrm{Bu}$ çalışma kapsamında ele alınan değişkenlerden birisi de katkı türüdür. Temeli yükleme kuramına dayanan katk1 türü değişkeni, olumlu ya da olumsuz sonuca yol açan etkenin yetenek (yetenek eksikliği) ya da çaba (çaba eksikliği) olması ile ilgilidir. Yürütülen bir dizi araştırmada yetenek ya da çaba nedeniyle yaşanan kazanç ve kayıp durumlarında hangi ilkeye göre yapılan pay dağılımının daha adil olarak algılandığını belirlemek amaçlanmıștır (Kayser ve Lamm, 1980; Lamm ve Kayser, 1978; Lamm, Kayser ve Schanz, 1983). Kayser ve Lamm (1980) tarafından yürütülen araştırma, insanların sonucun olumlu olduğu, ancak bu sonucun ortaya çıkması için gösterilen çaba açısından farklılıkların bulunduğu durumlarda ödülün katkıya, yani hakçalık ilkesine göre dağıtılmasını uygun bulduklarını göstermiştir. Sonucun olumlu olduğu, ancak bireylerin sonuca yetenek farklılıkları nedeniyle farklı düzeylerde katkı yaptığı durumlarda ise ödülün eşitlik ilkesine göre dağıtılması tercih edilmektedir. Buna karşın, sonucun olumsuz olduğu durumlarda, bu sonucun ortaya çıkmasına yapılan katkı ister yetenek, ister çaba eksikliği nedeniyle farklılık göstersin bedelin eşit dağıtılması öngörülmektedir. Yani, olumlu sonuç söz konusu olduğunda, duruma bağlı olarak hem hakçalık, hem de eşitlik ilkesine göre yapılan ödül dağıtımı adil bulunabilirken, sonuç olumsuz olduğunda bedelin sadece eşitlik ilkesine göre paylaştırılması adil bulunmaktadır. Araştırmacılar bu sonucu Weiner'in (1979) yükleme kuramından yararlanarak açıklamışlardır. Bu kurama göre, başarı ve başarısızlık nedenleri bireyler tarafindan yetenek, çaba, şans ve işin güçlüğü gibi durumlara, olumlu sonuçlar ise kişisel etmenlere yüklenme eğilimindedir. Bunun yanı sıra, insanlar çabayı da kişinin kendi kontrolünde olarak algıladıkları için, çaba farkının söz konusu olduğu durumda katkıya göre dağıtım yapma eğiliminde olmaktadırlar. Yetenek ise çabanın aksine kişinin kontrolünün dışındadır. Bu nedenle, sonuca yapılan katkı farklılıklarının yetenek farklılıklarından kaynaklandığ 1 durumlarda eşitlik ilkesine göre yapılan dağıtımlar daha adil bulunmaktadır (Şahin, 2003).

\section{İç-grup / Dış-grup üyeliği}

Bu çalışma kapsamında, kaynağı paylaştıran birey ile kaynağın paylaştırıldığı bireylerin aynı grubun ya da farklı grubun üyeleri olmaları, diğer bir deyişle iç-grup dış-grup ayrımı, pay dağıtımını etkileyebilecek etmenlerden biri olarak önerilmektedir.
Yapılan araştırmalar bireylerin ödül dağıtımında iç-grup yanlılığ 1 yapma eğiliminde olduğunu göstermiştir (Aberson, Healy ve Romero, 2000; Brewer, 1979; Mullen, Brown ve Smith, 1992; Tajfel, Billig, Bundy ve Flament, 1971). Ancak, bir grup araştırmacı olumlu kaynakların (örn. ödül, para) dağıtımında gözlenen iç-grup yanlılığının olumsuz kaynakların dağıtımına (örn. bedeller, masraflar, dışlayıcı davranışlar) genellenmesinin söz konusu olmadığını öne sürmektedir (Mummendey ve ark., 1992; Otten ve Mummendey, 1999). Otten ve Mummendey'e (1999) göre olumlu sonuçlar söz konusu olduğunda kişiler iç-grup üyelerini kayırmakta ve ödülden kendi grubundakilere daha fazla pay vermektedirler. Olumsuz sonuçlar söz konusu olduğunda ise gruplar arasında ayrım yapılmamakta ve bedel iç-grup üyeleriyle diş-grup üyelerine eșit olarak dağıtılmaktadır. Otten ve Mummendey (1999), bedellerin dağıtımında iç-grup yanlılığının görülmemesini, iç-grup üyelerini muaf tutarak bedelleri dış-grup üyelerine ödetmenin toplumsal açıdan kabul görecek gerekçelerle açıklanmasının güç olmasına bağlamaktadır. Olumsuz sonuçlar söz konusu olduğunda, bedellerinin diş-grup üyelerine ödetilmesinin bencil ve ahlaka aykırı bir davranış olarak alg1lanması tehlikesi vardır. Bu algıları değiştirecek makul gerekçeler bulmak ise oldukça güçtür. Olumlu sonuçlar söz konusu olduğunda, kişilerin ödül dağıtımında kendi gruplarını kayırmalarına bencilliklerini örtecek makul gerekçeler bulmaları daha kolaydır. Bu nedenlerle, Otten ve Mummendey’e (1999) göre, kişiler ödül dağıtımında iç-grup yanlılığı gösterirken, bedel dağıtımında bu eğilim söz konusu olmamaktadır.

Özetle, bu çalışmada, katkı türü (yetenek/çaba), payın niteliği (ödül/bedel) ve grup üyeliği (iç-grup/dışgrup) değişkenlerinin pay dağıtımının adil olarak alg1lanmasındaki rolü incelenmiştir.

\section{Yöntem}

\section{Katılimcilar}

Araştırma, Hacettepe Üniversitesi Psikoloji Bölümü'nde okuyan ve çeşitli bölümlerde okuyup 'Psikolojiye Giriş' dersi alan öğrencilerden oluşturulan 160 kişilik (144 kadın; 16 erkek) bir örneklemde yürütülmüştür. Katılımcılar, araştırmada yer alan 8 deneysel koşula seçkisiz olarak atanmışlardır. Erkek katılımcıların koşullara eşit dağılmasına özen gösterilmiştir.

\section{Veri Toplama Araçları}

Çalışmada veri toplama aracı olarak katkı türü (yetenek/çaba), payın niteliği (ödül/bedel) ve grup üyeliği (iç-grup/diş-grup) değişkenlerinin değişimlenmeleriyle oluşturulan deneysel koşulları temsil eden sekiz öykü kullanılmıştır. Bu öykülerde, birlikte bir proje hazırlayan 
ve başarılı ya da başarısız olan iki kişiden söz edilmektedir. Söz konusu iki kişiden biri iç-grup (aynı üniversitenin öğrencisi), diğeri diş-grup üyesi (başka bir üniversitenin öğrencisi) olup, yeteneği (yetenek eksikliği) ya da çabası (çaba eksikliği) nedeniyle sonuca daha az ya da daha fazla katkıda bulunmaktadır (Örnek öykü için, bkz. Ek-1).

Katılımcılar ilk bölümde başarı koşulunda ödülü, başarısızlık koşulunda bedeli nasıl paylaştıracaklarını belirtmişlerdir. Bunun için, öyküyü okuyan katılımc1lara ödül koşulunda, "Jüri değerlendirmesi sonucunda, bu öğrenciler hazırladıkları proje ile birinci olmuşlardır. Şimdi de 300TL ödülü aralarında paylaşacaklardır.” ve bedel koşulunda "Jüri değerlendirmesi sonucunda, bu öğrencilerin hazırladıkları proje dereceye girememiştir. Şimdi de geri ödenecek olan 300TL masrafi aralarında paylaşmaları gerekmektedir.” cümlesinin ardından öyküdeki iki öğrenciye bu miktarı nasıl pay edecekleri sorulmuştur. Katılımcılar bu miktarı iki öğrenci arasında istedikleri gibi pay etmişlerdir (örn., ilk kişiye 200, ikinci kişiye 100 ya da ilk kişiye 150 , ikinci kişiye 150 , vb.).

Bunun yanı sıra katılımcılar kendilerine araştırmac1 tarafından sunulan eşit ödül ya da bedel paylaştırma önerisini ne ölçüde adil bulduklarını 5 basamaklı ölçek üzerinde değerlendirmişlerdir.

\section{Bulgular}

Ödül İle Bedel Dağıtımına İlişkin Pay Dağıtımında Katkı Türü ve İç-Grup Üyeliğinin Etkisine Dair Bulgular

İlk soruda, 300 TL'nin birlikte proje hazırlayarak yarışmaya katılan iki kişi arasında ne şekilde bölüştürüldüğü incelenmiştir. Elde edilen verilere 2 (katkı türü: çaba/yetenek) x 2 (payın niteliği: ödül/bedel) x 2 (katk1da bulunan: iç-grup/dış-grup) x 2 (değerlendirilen: içgrup kişisi/diş-grup kişisi) olmak üzere 4 faktörlü ve son faktörde tekrar ölçümlü Varyans Analizi uygulanmıştır. Katılımcılar tarafından yapılan pay dağıtımının ortalama ve standart sapmaları Tablo 1'de gösterilmiştir.

Analiz sonuçlarına göre katkıda bulunan kişi $\mathrm{x}$ değerlendirilen kişi ikili ortak etki anlamlı bulunmuştur $F(1,152)=5.01, p<.05, h^{2}=.032$. Ayrica payın niteliği x katkıda bulunan kişi x değerlendirilen kişi üçlü ortak etki elde edilmiştir $F(1,152)=86.06, p<.001, h^{2}$ $=.361$. Bunun yanı sıra, payın niteliği x katkıda bulu-

Tablo 1. Katılımcılar Tarafından Yapılan Pay Dağıtımının Bağımıız Değişkenlere Göre Ortalama ve Standart Sapmaları

\begin{tabular}{|c|l|l|l|l|l|l|l|}
\hline \multicolumn{3}{|c|}{ Katkıda bulunan: İç-grup } & \multicolumn{4}{c|}{ Katkıda bulunan: D1ş-grup } \\
\hline \multicolumn{2}{|c|}{ Çaba } & \multicolumn{2}{|c|}{ Yetenek } & \multicolumn{3}{c|}{ Çaba } & \multicolumn{2}{c|}{ Yetenek } \\
\hline 1 & 2 & 1 & 2 & 1 & 2 & 1 \\
\hline $\begin{array}{l}\text { Ort }=188.75 \\
\mathrm{~S}=31.53\end{array}$ & $\begin{array}{l}\text { Ort }=111.25 \\
\mathrm{~S}=31.53\end{array}$ & $\begin{array}{l}\text { Ort. }=163.50 \\
\mathrm{~S}=22.07\end{array}$ & $\begin{array}{l}\text { Ort. }=136.50 \\
\mathrm{~S}=22.07\end{array}$ & $\begin{array}{l}\text { Ort. }=122.50 \\
\mathrm{~S}=27.83\end{array}$ & $\begin{array}{l}\text { Ort. }=177.50 \\
\mathrm{~S}=27.83\end{array}$ & $\begin{array}{l}\text { Ort. }=143.90 \\
\mathrm{~S}=13.40\end{array}$ & $\begin{array}{l}\text { Ort. }=161.10 \\
\mathrm{~S}=24.80\end{array}$ \\
\hline
\end{tabular}

\begin{tabular}{|c|c|c|c|c|c|c|c|}
\hline \multicolumn{8}{|c|}{ Bedel } \\
\hline \multicolumn{4}{|c|}{ Katkıda bulunan: İç-grup } & \multicolumn{4}{|c|}{ Katkıda bulunan: Dış-grup } \\
\hline \multicolumn{2}{|c|}{ Çaba } & \multicolumn{2}{|c|}{ Yetenek } & \multicolumn{2}{|c|}{ Çaba } & \multicolumn{2}{|c|}{ Yetenek } \\
\hline 1 & 2 & 1 & 2 & 1 & 2 & 1 & 2 \\
\hline Ort. $=125.00$ & Ort. $=175.00$ & Ort. $=145.00$ & Ort. $=155.00$ & Ort. $=174.00$ & Ort. $=126.00$ & Ort. $=147.50$ & Ort. $=147.50$ \\
\hline $\mathrm{S}=32.49$ & $\mathrm{~S}=32.49$ & $\mathrm{~S}=15.39$ & $\mathrm{~S}=15.39$ & $\mathrm{~S}=25.01$ & $\mathrm{~S}=25.01$ & $\mathrm{~S}=11.18$ & $\mathrm{~S}=25.52$ \\
\hline
\end{tabular}

Not. 1 = Değerlendirilen kişi: İç-grup, 2 = Değerlendirilen kişi: Dış-grup 
nan kişi $\mathrm{x}$ değerlendirilen kişi $\mathrm{x}$ katkı türü dörtlü ortak etki gözlenmiştir, $F(1,152)=33.00, p<.001, h^{2}=.178$. Anlamlı bulunan dörtlü ortak etki diğerlerini de içerdiği için çalışmada sadece bu dörtlü ortak etki yakından incelenmiş, grupların pay dağıtımı ortalamaları arasındaki anlamlı farklılıkları belirlemek amacıyla Tukey testleri uygulanmıştır.

Daha fazla çaba sarf eden kişi iç-gruptan olduğu zaman ödülden iç-gruptan olan kişiye (Ort. = 188.75) dış-gruptan olan kişiye $($ Ort. $=111.5)$ kıyasla daha fazla pay verilmiştir $(p<.01)$. Daha fazla çaba sarfeden kişi dış-gruptan olduğu zaman da ödülden, dış-gruptan olan kişiye (Ort. = 177.50) iç-gruptan olan kişiye (Ort. $=122.50$ ) kıyasla daha fazla pay verilmiştir. Buna göre; ister iç-gruptan ister dış-gruptan olsun daha fazla çaba harcayana ödülden daha fazla pay verilmiştir. Benzer biçimde yeteneğiyle daha fazla katkıda bulunan kişi iç-gruptan olduğu zaman ödülden, iç-gruptan olan kişiye $($ Ort. $=163.50)$ diş-gruptan olan kişiye $($ Ort. $=136.50)$ kıyasla daha fazla pay verilmiştir $(p<.05)$. Ancak, yeteneğiyle daha fazla katkıda bulunan kişi dış-gruptan olduğu zaman ödülden, diş-gruptan olan kişiye (Ort. = 161.10), iç-gruptan olan kişiye (Ort. $=143.90)$ kıyasla daha fazla pay verme eğilimi gözlenmekle birlikte bu fark anlamlı çıkmamıştır.

Daha fazla çaba sarf eden kişi iç-gruptan olduğu zaman bedel, iç-gruptan olan kişiye (Ort. = 175.00) k1yasla dış-gruptan olan kişiye $($ Ort. $=125.00)$ anlamlı düzeyde daha fazla miktarda ödettirilmiştir $(p<.01)$. Benzer şekilde, daha fazla çaba sarf eden kişi dış-gruptan olduğu zaman da bedel, iç-gruptan olan kişiye (Ort. = 174.00) diş-gruptan olan kişiye (Ort. $=126.00)$ kıyasla anlamlı düzeyde daha fazla miktarda ödettirilmiştir $(p<$
.01). Öte yandan, yeteneğiyle daha fazla katkıda bulunan kişi ister iç-gruptan, ister diş-gruptan olsun bedel, her iki tarafa da aynı miktarlarda pay ettirilmiştir.

Bunun yanı sıra, iç-grup üyesine verilen pay ile dış-grup üyesine verilen pay birbirine birebir bağıml (perfect collinearity) olduğundan yapılan tekrar ölçümlü varyans analizinde tekrar ölçümlü faktörü içermeyen gruplararası değişkenlerin temel ya da ortak etkileri analiz edilemediği için, tekrar ölçümlü varyans analizine ek olarak 2 (katkı türü: çaba/yetenek) x 2 (payın niteliği: ödül/bedel) x 2 (katkıda bulunan: iç-grup/dış-grup) faktörlü varyans analizi uygulanmıştır. Bağımlı değişken olarak her öyküde çok katkı sunana verilen pay ele alınmıştır. Analiz sonuçlarına göre, katkıda bulunan kişi $\mathrm{x}$ katkı türü x payın niteliği üçlü ortak etki gözlenmiştir, $F$ $(1,152)=38.75, p<.001, h^{2}=.203$.

Daha fazla çaba sarf eden kişi iç-gruptan olduğu zaman (Ort. = 188.75) diş-gruptan olan kişiye (Ort. $=122.50)$ kıyasla daha fazla ödül pay edilmiştir $(p<$ .001). Bedel söz konusu olduğunda ise, daha fazla çaba sarf eden kişi dış-gruptan olduğu zaman (Ort. = 174.00) iç-gruptan olan kişiye (Ort. $=125.00)$ kıyasla daha fazla bedel pay edilmiştir $(p<.001)$.

Ayrıca, daha yetenekli olan kişi iç-gruptan olduğu zaman (Ort. = 163.50) diş-gruptan olan kişiye (Ort. $=143.90)$ kıyasla daha fazla ödül pay edilmiştir $(p<$ .05). Bedel söz konusu olduğunda ise, daha yetenekli olan kişinin iç-gruptan olduğu koşul ile (Ort. = 174.00) dış-gruptan olduğu koşul (Ort. = 125.00) arasında anlamlı fark bulunmamıştır $(p=.739)$. Her iki analiz sonucu, ödül ile bedel dağıtımına ilişkin adillik algılarında katk1 türü ve iç-grup üyeliğinin etkisi Şekil 1'de gösterilmiștir.

\begin{tabular}{llccc}
\hline & \multicolumn{2}{c}{ Ödül } & Bedel \\
\cline { 2 - 4 } & İç-Grup & Diş-Grup & İç-Grup & Diş-Grup \\
\hline Çaba & Hakçalık & Hakçalık & Hakçalık & Hakçalık \\
\hline Yetenek & Eşit & Eşit & Sçit \\
\cline { 2 - 4 } & İç-grup - Diş-grup farkı & & \\
\hline
\end{tabular}

Şekil 1. Ödül İle Bedel Dağıtımına İlişkin Adillik Algılarında Katkı Türü ve İç-Grup Üyeliğinin Etkisi 
Tablo 2. Katılımcılar Tarafından Eşit Pay Dağıtımına İlişkin Adillik Algısının Bağımsız Değişkenlere Göre Ortalama ve Standart Sapmaları

\begin{tabular}{|c|c|c|c|c|c|}
\hline \multicolumn{2}{|c|}{ Katkıda Bulunan } & \multicolumn{2}{|c|}{ Katkı Türü } & \multicolumn{2}{|c|}{ Payın Niteliği } \\
\hline$\dot{I}_{\text {ç grup }}$ & Diş-grup & Çaba & Yetenek & Ödül & Bedel \\
\hline Ort. $=3.49$ & Ort. $=3.86$ & Ort. $=3.00$ & Ort. $=4.35$ & Ort. $=3.40$ & Ort. $=3.95$ \\
\hline $\mathrm{S}=1.35$ & $\mathrm{~S}=1.16$ & $\mathrm{~S}=1.25$ & $\mathrm{~S}=0.86$ & $\mathrm{~S}=1.34$ & $\mathrm{~S}=1.14$ \\
\hline
\end{tabular}

Katılımcıların Ödül ile Bedelin Eşit Dağıtımına İlişkin Adillik Algılarında Katkı Türü ve İç-Grup Üyeliğinin Etkisine Dair Bulgular

Katılımcıların çaba ve yetenekten oluşan farklı katk1 türlerini, ödül ve bedelden oluşan sonuçları ve iç-grup üyeliğini göz önünde bulundurarak, eşit pay dağıtımını ne derece adil bulduklarını öğrenmek amacıyla sorulmuştur. Katılımcılardan değerlendirmelerini 1 (olumsuz uç) ve 5 (olumlu uç) olmak üzere 5 basamaklı ölçek üzerinde yapmaları istenmiştir. Ölçümlerin ortalama ve standart sapmaları Tablo 2'de gösterilmiştir.

Verilere 2 (katkı türü: çaba/yetenek) x 2 (payın niteliği: ödül/bedel) x 2 (katkıda bulunan: iç-grup/dış-grup)
Varyans Analizi uygulanmıştır. Şekil 2'de izleneceği gibi katılımcılar, daha çok katkı gösteren dış-gruptan (Ort. = 3.86) olduğunda, eşit dağıtımı, daha çok katkı gösterenin iç-gruptan (Ort. $=3.49$ ) olduğu duruma göre daha adil bulduklarını belirtmişlerdir. Bunun yanı sıra, katkı türü temel etkisi de anlamlı düzeydedir, $F(1,152)=69.13, p$ $<.000, h^{2}=.313$. Katkı türünün yetenek olduğu durumda (Ort. = 4.35) eşit dağıtım, çabanın olduğu duruma (Ort. $=3.00)$ göre daha adil bulunmuştur. Son olarak, payın niteliği temel etkisi anlamlı bulunmuştur, $F(1,152)=$ 11.47, $p<.001, h^{2}=.070$. Yani, bedelin (Ort. $\left.=3.95\right)$ eşit dağıtımı, ödülün (Ort. = 3.40) eşit dağıtımından daha adil bulunmuştur.
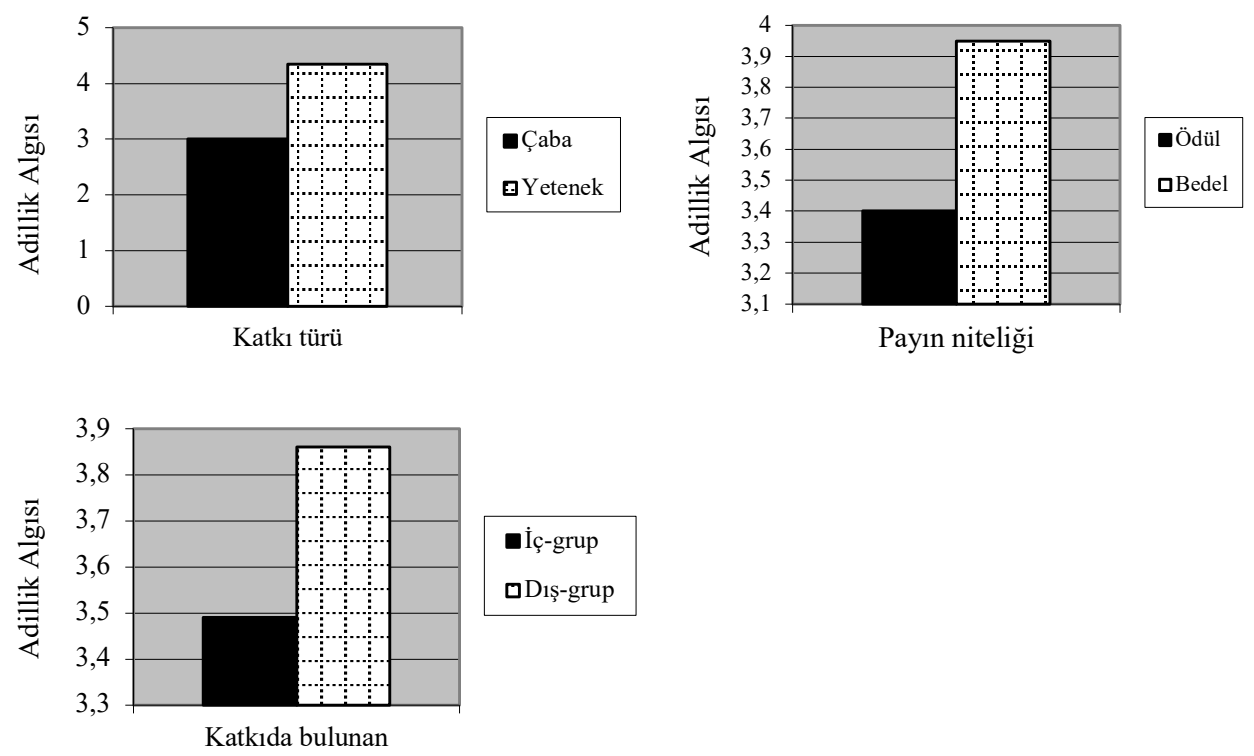

Şekil 2. Eşit Pay Dağıtımına İlişkin Adillik Algısında Katkı Türü, Payın Niteliği ve Katkıda Bulunan Kişi Temel Etkileri 


\section{Tartıșma}

$\mathrm{Bu}$ araştırmada genel olarak, ödül ile bedel dağıt1mına ilişkin adillik algılarının temelinde yatan süreçlerin farklı olup olmadığı, bireylerin bedel dağıtımı yaparken de iç-grup yanlılı̆̆1 gösterip göstermedikleri ve çaba ya da yeteneği nedeniyle olumlu ya da olumsuz bir sonuca daha fazla katkıda bulunan kişinin iç-grup ya da dış-grup üyesi olmasının pay dağılımına ilişkin tercihlerde bir değişmeye yol açıp açmadığı incelenmiştir.

Elde edilen bulgulara bakıldığında, daha fazla çaba sarf eden kişi iç-gruptan olduğu zaman iç-gruptan olan kişiye dış-gruptan olan kişiye kıyasla ödülden daha fazla pay verildiği görülmüştür. Aynı şekilde, daha fazla çaba sarfeden kiși dıș-gruptan olduğu zaman da ödülden, dış-gruptan olan kişiye iç-gruptan olan kişiye kıyasla daha fazla pay verilmiştir. Bu açıdan bakıldığında, ödül durumunda pay dağıtımı yapılırken, iç-grup yanlılığından ziyade ister iç-gruptan ister dış-gruptan olsun daha fazla çaba harcayana ödülden daha fazla pay verilmesi tercih edilmiștir. Diğer bir değişle, çaba söz konusu olduğunda ödül dağıtımında katkıya göre dağıtım yani hakçalık normu daha çok tercih edilmiştir. Bölüşümsel adalet ile ilgili literatüre bakıldığında, genellikle herhangi bir ürünün emek verilerek ortaya konduğu durumlarda bireylerin katkıya göre pay dağıtımını daha adil bulduğu görülmektedir (Furby, 1986; Tyler ve Smith, 1998). Bu bakımdan araştırma sonuçları literatürle tutarlıdır. Katkı türü olarak çabanın pay dağıtım kararında böyle başat bir rol oynaması, iç-grup ve dış-grup değişkenlerinin etkisiz kalması, sorumluluk yüklemesinin önemine bağlanabilir. Weiner'in (Weiner, Jones, Kanouse, Kelley, Nisbett ve Valins 1971; Weiner,1979) yükleme kuramı çerçevesinde, insanlar çabayı kişinin kendi kontrolünde olarak algılamaktadırlar; nitekim yapılan araştırmalarda başarı ve başarısızlık yüklemesinde çabanın önemsendiği ve ödüllendirildiği gözlenmektedir (Weiner ve Kukla, 1970; Weiner, 1979; 1985; 1986; 1995). O halde, çaba farkının söz konusu olduğu durumda katkıya göre dağıtım yapma bulgusu yazılı kaynaklarla uyuşmaktadır.

Çaba durumuna benzer biçimde, yeteneğiyle daha fazla katkıda bulunan kişi iç-gruptan olduğu zaman da, iç-gruptan olan kişiye diş-gruptan olan kişiye kıyasla ödülden daha fazla pay verilmiştir. Yani katılımcılar yetenek söz konusu olduğunda, ödül dağıtımı yaparken hakçalık ilkesine başvurmuştur. Bu sonuç, yetenek fark1 söz konusu olduğunda eşit dağıtımın tercih edildiği sonucuna varan çalışmaların (Lamm ve Kayser, 1978; Kayser ve Lamm, 1980; Lamm, Kayser, Schanz, 1983; Şahin, 2003) bulgularıyla uyuşmamaktadır.

Diğer yandan, yeteneğiyle daha fazla katkıda bulunan kişi diş-gruptan olduğu zaman diş-gruptan olan kişiye, iç-gruptan olan kişiye kıyasla ödülden daha fazla pay verme eğilimi gözlenmekle birlikte bu fark anlamlı çıkmamıştır. Yani, katılımcılar daha yetenekli olan dışgrup üyesi olduğunda eşit dağıtmayı tercih etmişlerdir. Buna göre ödül dağıtımı yapılırken, yetenek ile katkı söz konusu olduğunda, çaba ile katkının olduğu durumun aksine, iç-grup/dış-grup ayırımı gözlenmektedir.

$\mathrm{Bu}$ durumda iç-grup üyeliğinin ödül dağıtımını belirlemede bir ara değişken olabileceği ihtimali gündeme gelmektedir. Bu araştırmada, yetenek söz konusu olduğunda eşit dağıtımın tercih edildiği sonucuna varan araştırmaların aksine hakçalık ilkesinin kullanılması, bireylerin iç-grup yanlılı̆̆1 yapma eğiliminde olduğunu gösteriyor olabilir. Nitekim, minimal grup deseni çerçevesinde araştırmalar yapan Tajfel ve arkadaşlarının (1971) elde ettiği bulgular, katılımcıların kendi gruplarını önemsiz bir temele göre gruplara ayrılmalarına, dağıtım yaptıkları kişileri hiç tanımamalarına, onlarla hiç geçmişleri ve muhtemelen bir gelecekleri olmamalarına ve kendileri ödülden pay almayacak olmalarına yani bireysel bir çıkarları olmamalarına rağmen büyük oranda kayırdıklarını göstermiştir. O halde katılımcılar ödül dağıtırken yeteneğiyle katkıda bulunan kendi üniversitesinden olduğunda katkıya göre, diğer üniversiteden olduğunda eşit dağıtarak bir yanlılık göstermiş olabilir.

Bedel söz konusu olduğunda ise, daha fazla çaba sarf eden kiși dıș-gruptan olduğu zaman iç-gruptan olan kişiye kıyasla daha fazla bedel pay edilmiştir. Benzer şekilde, daha fazla çaba sarf eden kişi dış-gruptan olduğu zaman da bedel, diş-gruptan olan kişiye kıyasla iç-gruptan olan kişiye anlamlı düzeyde daha fazla miktarda ödettirilmiştir. Yani çaba söz konusu olduğunda, katılımcılar tarafindan her iki durumda da bedelin hakçalık ilkesine uygun olarak dağıtılması tercih edilmiştir. $\mathrm{Bu}$ bulgunun da yine çabanın pay dağıtımında ne kadar önemli bir rolü olduğuna işaret ettiğini söyleyebiliriz.

Katk1 türü olarak yeteneğin söz konusu olduğu duruma baktığımızda ise daha fazla katkıda bulunan kişi ister iç-gruptan, ister diş-gruptan olsun, bedelin her iki tarafa da aynı miktarlarda pay ettirildiğini görmekteyiz. Yani yeteneğiyle katkıda bulunan kim olursa olsun, bedel her iki tarafa da eşit ödettirilmektedir. O halde, yetenek söz konusu olduğu zaman da, çabada olduğu gibi bedel ödettirme açısından iç-grup/dış-grup ayrımı yapılmamaktadir.

Yetenek söz konusu olduğunda ödülü dağıtırken iç-grup yanlılığı yapılmasını sosyal kimlik kuramı (Tajfel, 1982; Tajfel ve Turner, 1979) ile açıklamak mümkün görünmektedir. Kurama göre, insanlar olumlu bir sosyal kimlik edinmek ve benlik saygılarını yükseltmek için sosyal karşılaştırma yaparken, kendi gruplarını kayırarak algılama ve diğer grubu da küçümseme yönünde bir yanlılık göstererek, iç-grup yanlılığı yaparlar. Yani iç-grup üyesinin yeteneği ile daha çok katkıda bulunduğu durum- 
da ödülden daha fazla pay alması kuramın varsayımı ile örtüşmektedir. Nitekim bu bulguyla paralel olarak Aydın’ın (1991) çalışmasında katılımcılar, pek çaba göstermeden yeteneği ile başarılı olan birinin yerinde olmayı, fazla yetenekli olmayıp çok çaba göstererek aynı derecede başarılı olan birinin yerinde olmaya kıyasla daha çok tercih etmişlerdir. O halde başarıların yeteneğe yüklenmesi kişinin benlik değeri açısından daha değerli olduğu için (Covington ve Omelich, 1979), kişiler iç-grup üyesinin yeteneği ile daha çok katkıda bulunduğu durumda belki de iç-grup yanlılığı yapmaktadırlar. Bununla ilişkili olarak, bu çalışmanın sonuçlarına göre çaba söz konusu olduğunda iç-grup ve dış-grup ayrımı yapılmaması, belki de çabasıyla daha çok katkıda bulunmanın benlik değerini yükseltici etkisi olmamasından kaynaklanıyor olabilir.

Öte yandan, çaba harcayarak daha çok katkıda bulunulduğu zaman iç-grup yanlılığı gösterilmemesi bulgusunu, literatürde Marques, Yzerbyt ve Leyens'in (1988) kara koyun etkisi (black sheep effect) kavramıla da açıklamak mümkün gibi görünmektedir. Bu kavram gruplar arası ilişkiler açısından, sosyal olarak arzulanır üyelerin yüceltilirken, arzu edilmeyen üyelerin aşağılanması durumunu açıklamak için kullanılmıştır. Yazarlara göre, grup normlarını ihlal eden, olumsuz davranışlarda bulunan, grup kimliğini zedeleyen, istenmeyen grup üyeleri, grup normlarını ihlal eden bir dış-grup üyesine kıyasla daha olumsuz algılanmaktadır. Miller'a (2001) göre, olumsuz bir davranış söz konusu olduğunda içgrup üyesinin uyandırdığı öfke duygusu diş-grup üyesinin uyandırdığı öfke duygusuna kıyasla daha fazladır. Dış-grup üyelerinden birinin olumsuz davranışı karşısında bireyler, "buna nasıl cüret eder" tepkisini verirken, iç-grup üyelerinden birinin olumsuz davranışı karşısında bireyler, "bunu bize nasil yapar" tepkisinde bulunurlar. Böyle bir durumda, iç-grup üyesinin aldığı tepki, dış-grup üyesinin aldığı tepkiden daha olumsuzdur. Bu açılardan bakıldığında, koşullar ne olursa olsun bireyler her durumda iç-grup yanlılığı gösterme eğilimindedirler demek yanlış bir kanı olmaktadır. Yani daha çok çaba gösteren diş-grup üyesi olduğu zaman iç-grup yanlılığına başvurulmaması, daha fazla çaba sarfetmeyen içgrup üyesini, "gruba olumsuz bir etiket getirdiği için", bir nevi cezalandırmak niyetiyle gerçekleşmiş olabilir. İç-grup yanlılığının yetenek söz konusu olduğunda gösterilmesi, çaba söz konusu olduğunda ise gösterilmemesi konusunda hangi açıklamanın geçerli olduğu araştırılması gereken bir konu olarak ortaya çıkmaktadır.

$\mathrm{Bu}$ sonuçlara bakıldığında, bulguların genel olarak bölüşümsel adalet literatürüyle uyuştuğundan söz edilebilir. Çaba daha çok kişinin kontrolünde algılandığı için hem olumlu hem olumsuz sonuç durumunda katkıya göre dağıtım eşit dağıtıma kıyasla daha adil olarak alg1lanmaktadır. Diğer yandan yetenek söz konusu olduğun- da, olumsuz durumda, bedelin eşit dağıtımı katkıya göre dağıtıma kıyasla daha adil bulunmuştur. Yetenek, çabanın aksine, kişinin kendi kontrolünün dişında olduğu için duruma kişisel sorumluluk yüklenmemesi nedeniyle kaybın eşit dağıtımının daha adil olarak algılanması yükleme kuramıyla (Weiner ve ark., 1971; Weiner, 1979; 1986; 1995) tutarl1lık göstermektedir.

Araştırmada katılımcılardan pay dağıtımı yapmaları istenmesinin dışında bir de eşit pay dağıtımını ne derece adil bulduklarını belirtmeleri istenmiştir. Daha önce değinildiği gibi pay dağıtımı ile ilgili araştırmaların çok azında, açık bir şekilde 'adil' dağıtım yapılmasının istendiği ve istenmediği durumlarda, katılımcının nasıl hareket ettiği karşılaştırılmıştır. Bunu anlamak için Lamm ve Schwinger (1983) yaptıkları araştırmada her iki durumda da gereksinim ilkesine başvurulduğunu, bu durumun fark yaratmadığını belirtmişlerdir. Ancak bu görüş, bu araştırmanın bulgularıyla pek uyuşmamaktadır. Katılımcılardan kendilerinin pay dağıtımı yapması istendiğinde gözlenen değişkenler arası ortak etki, adil dağıtımın özellikle belirtildiği durumda gözlenmemiş; sadece temel etkiler anlamlı bulunmuştur. İlk olarak, katkı türünün yetenek olduğu durumda eşit dağıtım, çabanın söz konusu olduğu duruma göre daha adil bulunmuştur. Bu bulgu yine genel olarak bölüşümsel adalet konusunda yapılan çalışma bulgularıyla uyuşmaktadır (Lamm ve Kayser, 1978; Kayser ve Lamm, 1980; Lamm ve ark., 1983; Şahin, 2003; Şahin ve Aydın, 2004). Bu sonucun ödül ya da bedele, iç-grup ya da diş-gruba göre değişmemesinin nedeni, daha önce değindiğimiz gibi, bireylerin adalet algısında sorumluluk yüklemesinin önemi olabilir.

Bir diğer bulguya göre, bedelin eşit dağıtımı, ödülün eşit dağıtımından daha adil bulunmuştur. Bu durum, Sabbagh ve Schmitt'in (1998) aktardığ1 pek çok çalışmada (Brickman ve ark., 1981; Meeker and Elliot, 1987; Murphy-Berman, Berman, Purnima, Pachauri ve Kumar, 1984; Törnblom ve Jonsson, 1987) elde edilen sonuçlardandır: Katılımcılar olumlu sonuçlar olduğunda katkıya göre pay dağıtımını, olumsuz sonuçlar olduğunda ise eşit ya da gereksinime göre dağıtımları daha adil bulmuşlardır. Oysa bir önceki durumda, yani kişilerden kendilerinin dağıtım yapmaları istendiğinde, eğer uyarıcı kişilerden biri çabasıyla daha çok katkıda bulunduysa, bedelin eşit değil katkıya göre dağıtılması tercih edilmişti. Adil dağıtımın belirtildiği bu durumda ise, böyle bir ayrıma gidilmeyerek doğrudan bedelin eşit dağıtılması adil algılanmaktadır. Bu da bize kişilerden doğrudan dağıtım yapmaları istendiğinde elde edilen sonuçlarla, adil olmanın belirtildiği durumda verilen karar arasında, Lamm ve Schwinger'in (1983) belirttiğinin aksine, fark olabileceğini göstermektedir. Bu durumda "kişiler pay dağıtımı yaparken, her zaman adil dağıtım yapmaya özen gösteriyorlar" demek güçleşmektedir. 


\section{Sonuç ve Öneriler}

$\mathrm{Bu}$ araştırma ödül ve bedel bölüşümüne ilişkin haklılık algılarında katkı türü ve iç-grup üyeliğinin etkisini incelemek amacıyla yürütülmüştür. Günümüze kadar bu alanda yapılan pek çok araştırma olmuş ancak ödül ve bedel dağııımına ilişkin adillik algılarının temelinde farklı süreçler yatıp yatmadığı, bireylerin bedel dağıtımı yaparken de iç grup yanlıllı̆ 1 gösterip göstermedikleri ve çaba ya da yeteneği nedeniyle olumlu ya da olumsuz bir sonuca daha fazla katkıda bulunan kişinin iç-grup ya da dış-grup üyesi olmasının pay dağılımına ilişkin tercihlerde bir değişmeye yol açıp açmadığı gibi soruların yanitlarında tutarsılzlıklar görülmüştür. Araştırma sonucunda, genel olarak, ödül ve bedel dağıtımına ilişkin adillik algılarının temelinde benzer süreçler yattığı, kişilerin bedel dağıtımında iç-grup yanlılı̆̆ı göstermedikleri ve daha çok yetenekli olan iç-gruptan olduğunda ödülün hakçalık ilkesine göre, dış-gruptan olduğunda eşitlik ilkesine başvurularak yapıldığı ve yalnızca bu durumda iç-grup yanlılığına başvurdukları gözlenmiştir.

Katılımcıların pay dağıtımı yaparken iç-grup yanlılı̆̆1 göstermeyip kendilerinden adil olmaları beklendiğinde daha açık bir şekilde iç-grup yanlllı̆̆ına başvurmalarının nedenini anlamak için yeni görgül araştırmalara ihtiyaç vardır. Bu sonucun araştırmanın bazı sınırlılıklarından kaynaklanıyor olması da mümkündür.

Örneğin, iç-grup diş-grup değişimlemesinin, uyar1c1 kişilerin iki farklı üniversiteden olması şeklinde gerçekleştirildiği bu çalışmanın sonuçları, farklı türde bir iç-grup dış-grup tasarlandığında elde edilen sonuçlarla tutarlılık göstermeyebilir. Gerçek hayatta kişilerin birbiriyle kesişen birçok iç-grup ve dış-grupları olduğu düşünüldüğünde, katılımcıyla aynı okuldan olan ama cinsiyeti açısından farklı olan kişi onun hem iç hem dış-grubu olabilir.

Literatürde, kişiler arasında yarışma havasının olup olmamasının, farklı kültür yapılarının, durumun farazi olup olmamasının pay dağıtım ilkelerinde değişmeye yol açabildiğini ortaya koyan araştırmalar mevcuttur. Bu nedenle, yarışma havasının olmadığı durumda, farklı bir kültür yapısında ya da gerçek hayatta bu araştırmanın bulgularından farklı bulgular elde edilebilir. Ayrıca, bu çalışmada erkek katılımcıların her koşula eşit şekilde dağıtılmasına dikkat edilmesine rağmen cevaplayıcıların çoğunu kadın katılımcılar oluşturmaktadır. Bu durum da araştırmanın kısıtlılıklarından biridir. Zira cinsiyet açısından dağılımın daha eşit olduğu bir araştırmada farklı bulguların elde edilmesi ihtimali söz konusu olabilir.

\section{Kaynaklar}

Aberson, C. L., Healy, M. R., \& Romero, V. L. (2000). Ingroup bias and self-esteem: A meta analysis. Personality and Social Psychology Review, 4, 157173.

Adams, J. S. (1965). Inequity in social exchange, Berkowitz, L. (ed.) Advances in experimental social psychology içinde (267-299). New York: Academic Press

Akgün, S. (2004). Bölüșümsel Adalet Normlarının Çevresel Belirleyicileri: İlişki Türü ve Sorumluluk Yükleme. Türk Psikoloji Dergisi, 19, 1-18.

Aydın, O. (1991). Başarı ve başarısızlıkların nedenlerine ilişkin açıklamaların duygusal sonuçları. Hacettepe Üniversitesi Edebiyat Fakültesi Dergisi, 8, 83-99.

Brewer, M.B. (1979). In-group baises in the minimal intergroup situation: A cognitive motivational analysis. Psychological Bulletin, 86, 307-324.

Brickman, P., Folger, R., Goode, E., \& Schul, Y. (1981). Microjustice and macrojustice, Lerner, M. J. \& Lerner, S. C. (eds.) The Justice Behavior in Social Behavior içinde (173-202). New York: Plenum Press.

Covington, M. V. \& Omelich, C. L. (1979). It's best to be able and virtious too: Student and teacher evaluative responses to sucessful effort. Journal of Educational Psychology, 71, 688-700.

Deutsch, M. (1975). Equality, equity and need: What determines which value will be used as a basis of distributive justice. Journal of Social Issues, 31, 37-149.

Deutsch, M. (1985). Distributive Justice: A socialpsychological perspective. New Haven, CT: Yale University Press.

Elster, J. (1989). Social norms and economic theory. The Journal of Economic Perspectives, 3, 99-117.

Furby, L. (1986). Psychology and justice, Cohen, R. L. (ed.) Justice: Views from the Social Sciences içinde (153-203). New York: Plenum Press.

Goodwin, B. (1992). Justice by lottery. Chicago: University of Chicago Press.

Homans, G. (1961). Social Behaviour: Its Elementary Forms. London: Routledge and Kegan Paul.

Kayser, E., \& Lamm, H. (1980). Input integration and input weighting in decision on allocations of gain and losses. European Journal of Social Psychology, 8, 275-278.

Lamm, H., \& Kayser, E. (1978). The allocation of monetary gain and loss following dyadic performance: The weight given to effort and ability under conditions of low and high intra-dyadic attraction. European Journal of Social Psychology, 8, 275-278. 
Lamm, H., Kayser, E., \& Schanz, V. ( 1983). An attributional analysis of interpersonal justice: Ability and effort as inputs in the allocation of gain and loss. Journal of Social Psychology, 119, 269-281

Lamm, H. \& Schwinger, T. (1980). Norms concerning justice: Are needs taken into consideration in allocation decisions?. Social Psychology Quarterly, 43, 425-429

Lamm, H. \& Schwinger, T. (1983). Need consideration in allocation decisions: Is it just? Journal of Social Psychology, 119, 205-209.

Lerner, M. J. (1974). The Justice Motive: 'Equity' and 'Parity' Among Children. Journal of Personality and Social Psychology, 29, 538-550.

Lerner, M.J. (1975). The justice motive in social behavior: Introduction. Journal of Social Issues, 31, 1-19.

Lerner, M.J. (1977). The justice motive: Some hypotheses as to its origins and forms. Journal of Personality, 45, 1-52.

Leventhal, G. S. (1976). Fairness in social relationships, Thibaut, J. W., Spence, J. T. \& Carson, R. C. (Eds.) Contemporary Topics in Social Psychology içinde. Morristown, NJ: General Learning Press.

Marques, J., Yzerbyt, V., \& Leyens, J.-Ph. (1988). The 'Black Sheep Effect': Extremity of judgments toward ingroup members as a function of group identification. European Journal of Social Psychology, 18, 1-16.

Meeker, B. F. \& Elliot, G. C. (1987). Counting the costs: Equality and the allocation of negative group products. Social Psychology Quarterly, 50, 7-15.

Miller, D. T. (2001). Disrespect and the experience of injustice, Fiske, S. T., Schacter, D. L. \& Zahn-Waxler, C. (eds.) Annual Review of Psychology içinde (527-553). Palo Alto, CA: Annual Reviews.

Mullen, B., Brown, R., \& Smith, C. (1992). Ingroup bias as a function of salience, relevance and status: An integration. European Journal of Social Psychology, 22, 103-122.

Mummendey A, Simon B, Dietze C, Grunert M, Haeger $\mathrm{G}$, et al. (1992). Categorization is not enough: intergroup discrimination in negative outcome allocations. Journal of Experimental Social Psychology, 28, 125-44.

Murphy-Berman, V. \& Berman, J. J. (2002). Cross-Cultural Differences in Perceptions of Distributive Justice. Journal of Cross-Cultural Psychology, 33, 157-170.

Murphy-Berman, V., Berman, J. J., Purnima, S., Pachauri, A., \& Kumar, P. (1984). Factors affecting allocation to needy and meriterious recipients:A cross-cultural comparison. Journal of Personality and Social Psychology, 46, 1267-1272.
Otten, S. \& Mummendey, A. (1999). To our benefit or at your expense? Justice considerations in intergroup allocations of positive and negative resources. Social Justice Research, 12, 19-38.

Sabbagh, C. \& Schmitt, M. (1998). Exploring the structure of positive and negative justice judgements. Social Justice Research, 11, 381-396.

Scott, J. T., Matland, R. E., Michelbach, P. A., \& Bornstein, B. H. (2001). Just deserts: An experimental study of distributive justice norms. American Journal of Political Science, 45, 749-767.

Schwinger, T. (1986). The need principle of distributive justice. In Bierhoff, H. W. and Cohen, R. I. (Eds.) Justice in Social Relations, 211-225. New York: Plenum Pres.

Şahin, D. N. (2003). Ödül ve bedel bölüşümüne ilişkin haklılık algısında katkı türü ve pay dağıtımının etkisi. Türk Psikoloji Dergisi, 18, 17-36.

Şahin, D. N. (2006). Cinsiyet, fiziksel sağlık ve yarışma durumunun pay dağıtımına ilişkin adalet algısı üzerindeki etkileri. Hacettepe Üniversitesi Edebiyat Fakültesi Dergisi, 23, 57-74.

Şahin, D. N. \& Aydın, O. (2004). Ödül dağıtımında eşitlik hakçalık ve gereksinim ilkelerinin çalışma arkadaşının tercihi üzerindeki etkileri: Özçıkar eğiliminin bir göstergesi. 3P Psikiyatri Psikoloji Psikofarmakoloji Dergisi, 4, 287-294.

Tajfel, H. (1982). Social psychology of intergroup relations. Annual Review of Psychology, 33, 1-39.

Tajfel, H., Billig, M. G., Bundy, R. P. \& Flament, C. (1971). Social categorization and intergroup behavior. European Journal of Social Psychology, 1, 149-178.

Tajfel, H., \& Turner, J. C. (1979). An integrative theory of intergroup conflict. Worchel S., Austin W. G. (eds.) The social psychology of intergroup relations içinde. Monterey, CA: Brooks/Cole.

Törnblom, K.Y., \& Ahlin, E. (1998). Mode of accomplishing positive and negative outcomes: Its effect on fairness evaluations. Social Justice Research, 11, 423-442.

Törnblom, K. Y., \& Jonsson, D. R. (1985). Subrules of the equality and contribution principles: Their perceived fairness in distribution and retribution. Social Psychology Quarterly, 48, 249-261.

Törnblom, K. Y. \& Jonsson, D. R. (1987). Distribution and retribution: The perceived justice of the contribution and equality principles for cooperative and competitive relationships. Acta Sociologica, 30, 25-52.

Törnblom, K.Y., Mühlhausen, S.M., \& Jonsson, D.R. (1991). The allocation of positive and negative outcomes: When is the equality principle fair for both?, Vermunt R. \& Steensma, H. (eds.) Social Justice in Human Relations içinde, (59-100). New York: Plenum Press. 
Tyler, T. R. \& Smith, H. (1998). Social justice and social movements, Gilbert, D., Fiske, S., Lindzey, G. (eds.) Handbook of Social Psychology içinde (595629). N.Y.: McGraw-Hill.

Weiner, B. (1979). A theory of motivation for some classroom experiences. Journal of Educational Psychology, 71, 3-25.

Weiner, B. (1985). 'Spontaneous' causal thinking. Psychological Bulletin, 97, 74-84.

Weiner, B. (1986). An Attributional Theory of Motivation and Emotion. New York: Springer-Verlag.

Weiner, B. (1995). Judgments of Responsibility. New York: Guilford.

Weiner, B., Jones, E. E., Kanouse, D. E., Kelley, H. H., Nisbett, R. E. \& Valins, S. (1971). Attribution: Perceiving the causes of behavior. Morristown, $\mathrm{NJ}$ : General Learning Pres.

Weiner, B. \& Kukla, A. (1970). An attributional analysis of achievement motivation. Journal of Personality and Social Psychology, 15, 1-20.
Ek-1.

Hande ve Oya psikoloji bölümünde okuyan iki üniversite öğrencisidir. İlanlara bakarken, 'Gelişim Psikolojisi Araştırmalarını Teşvik' konulu bir proje yarışması duyurusu görürler. Duyuruda, birinciliğe layık görülen projenin, 300 TL değerinde ödüllendirileceği yazmaktadır. Hacettepe Üniversitesi'nde okuyan Hande ve Orta Doğu Teknik Üniversitesi'nde okuyan Oya yarışmaya birlikte katılırlar. Her ikisi de eşit yetenekli olan bu öğrenciler, öne sürdükleri yaratıcı fikirler üzerinde tartışarak proje taslağının oluşmasına eşit derecede katkıda bulunmuşlardır. Ancak projenin devamında, literatür taraması, ilgili kişilere ulaşılması, görüşmeler yapılması gibi aşamalarda Oya (ODTÜ) pek çaba göstermezken, vaktinin büyük bölümünü bu projeye ayıran Hande (Hacettepe Ü.) daha çok çaba harcamıştır.

Jüri değerlendirmesi sonucunda, bu öğrenciler hazırladıkları proje ile birinci olmuşlardır. Şimdi de 300TL ödülü aralarında paylaşacaklardır. 


\title{
Summary \\ The Effect of Effort/Ability Based Contributions and In-group Membership on the Perceived Fairness of Positive and Negative Outcomes
}

\author{
Suzan Ceylan-Batur \\ TOBB University of Economics \& Technology
}

For decades, social psychologists have been interested in identifying to what extent individuals perceive their share fair and the principles and factors involved in this evaluation (Akgün, 2004; Deutsch, 1975, 1985; Lamm \& Schwinger, 1980; Sabbagh \& Schmitt, 1998; Scott, Matland, Michelbach, \& Bornstein, 2001; Şahin, 2006). Research on this subject in social psychology are carried out under the title of distributional justice. Although the first researchers studying distributional justice assumed that the same processes were underlying the fairness perception in relation to distribution of both rewards and costs (Kayser and Lamm, 1980; Lamm and Kayser, 1978), in the forthcoming years the researchers suggested that they might be different (Sabbagh ve Schmitt, 1998; Törnblom ve Ahlin, 1998). The findings of the studies on these two different views did not reveal a robust conclusion supporting either of them (Kayser and Lamm, 1980; Lamm and Kayser, 1978; Lamm, Kayser and Schanz, 1983; Şahin, 2003). In addition, there were inconsistences in the answers to questions such as whether individuals show in-group bias when distributing also the costs, and whether the person who contributes to a positive or a negative outcome through her/his effort or talent belongs to an ingroup or an out-group would lead to a change in preferences regarding the distribution of justice (Mummendey et al., 1992; Otten and Mummendey, 1999; Şahin, 2003).

Therefore, further research is needed on the processes underlying the perceptions of fairness regarding allocation of positive and negative outcomes. In this study, it is aimed to examine the factors that play a role in whether or not the allocation decision is perceived as fair. In this context, the principle of resource allocation (equality, equity), the nature of the allocation (reward, cost), the type of contribution (effort, ability) and the group membership of the person who is distributed (ingroup, out-group) are examined.

\section{Resource allocation principles}

Studies on distributional justice revealed that different principles of resource allocation are employed; people use three different principles during the allocation of resources: equality, equity, and need (Deutsch, 1975; Leventhal, 1976). In the scope of this paper, equality and equity will be examined. The equity principle requires to allocate a resource based on one's contribution (Adams, 1965; Homans, 1961). In other words, the individual who contributes more should receive the reward more, and pay less cost. On the other hand, the equality principle requires equal distribution of awards and costs. According to this principle, all shares should be allocated equal, regardless of the contribution of individuals (Leventhal, 1976; Schwinger, 1986).

The nature of the allocation: Reward and Cost In the initial studies on distributional justice, fairness perceptions about the distribution of rewards were examined, but the distribution of costs was ignored with the assumption that the same processes were the basis of the perceptions about the allocation of positive and negative outcomes. However, further studies revealed different processes playing role in distribution of rewards and costs. For example, researchers found that in the case of positive outcomes, the equity principle is perceived as more fair than the equality principle, whereas in the case of negative outcomes equality principle is preferred (Brickman, Folger, Goode and Schul, 1981; Elster, 1989; Goodwin, 1992; Kayser and Lamm, 1980; Törnblom and Jonsson , 1985).

Address for Correspondence: Asst. Prof. Suzan Ceylan-Batur, TOBB University of Economics \& Technology, Faculty of Science and Literature, Department of Psychology, Söğ̈̈tözü Caddesi No:43, Söğütözü, 06560 Ankara.

E-mail: scbatur@etu.edu.tr 
The type of contribution: Effort and Ability

The research carried out by Kayser and Lamm (1980) showed that when the outcome is positive and when people contribute with different levels of effort, the equity principle is perceived as more fair. When people contribute with different levels of ability, then the equality principle is more preferred. On the other hand, when the outcome is negative regardless of the type of contribution, people find it appropriate to distribute the cost according to the equality principle. That is to say, when the positive outcome is concerned, the distribution of the reward is made in accordance with either the equality or the equity principle, but when the outcome is negative, people perceive fair to allocate the cost according to the equality principle only.

\section{In-group and Out-group membership}

Research has shown that individuals tend to have in-group bias in the distribution of rewards (Aberson, Healy, \& Romero, 2000; Brewer, 1979; Mullen, Brown \& Smith, 1992; Tajfel, Billig, Bundy \& Flament, 1971). However, a group of researchers suggests that in-group bias observed in the distribution of positive outcomes (eg., reward, money) does not involve the allocation of negative outcomes (eg., costs, exclusionary behaviors) (Mummendey et al., 1992; Otten and Mummendey, 1999). According to Otten and Mummendey (1999), when positive outcomes are concerned, individuals favor members of their in-group and give more shares to the ones in their group. However, in the case of negative outcomes, no distinction is made between the groups and the cost is evenly distributed to in-group members and out-group members.

In summary, in this study, the role of contribution type (talent / effort), the nature of allocation (reward / cost) and group membership (internal-group / external-group) in distributional justice has been examined.

\section{Method}

160 university students (144 women; 416 men) in Ankara participated in the study. Participants were randomly assigned one of the 8 experimental conditions. Based on their condition participants read a vignette and answered the questions. In these vignettes, two successful or unsuccessful students are preparing a project together. One of these two students is in-group of the participant (i.e., student of the same university) and the other is an out-group member (i.e., student of another university) and contributes more or less to the result due to the ability (or lack of ability) or effort (or lack of effort). Participants were asked to share the reward or the cost between two students, and then they were asked to rate the degree of fairness of the distribution of equal outcomes.

\section{Results}

The results revealed that when the contribution type is effort, participants allocated both the rewards and the costs according to equity norm. When the contribution type is ability, participants allocated costs equally. However, when the target person who contributed more with a higher ability is in-group member, the reward is distributed proportionally; while the person is out-group member, the reward is equally distributed. The equal distribution is judged to be fairer by the participants when the contribution type is ability rather than effort; when the outcome is cost rather than reward; and when the person who contributed more is out-group member rather than in-group member.

\section{Discussion}

Results showed that when an in-group member display more effort, people are likely to allocate more positive resource to this in-group member than the outgroup member. Similarly, when an out-group member display more effort, people are likely to allocate more positive resource to out-group member than the in-group member. From this point of view, in the case of reward, it is preferred to give more to the person who display more effort, regardless their group membership. In other words, in the case of effort, distribution of rewards according to contribution is more preferable.

When we look at the literature on distributional justice, it is suggested that individuals tend to have a fairness perception according to the contribution level, in the cases where any outcome is reached by an effort (Furby, 1986; Tyler and Smith, 1998). In this regards, finding of this study is consistent with the literature. The fact that the effort as a type of contribution plays such a dominant role in the distribution decision, the ineffectiveness of group membership can be attributed to the importance of the burden of responsibility. According to Weiner's theory of attribution (Weiner, Jones, Kanouse, Kelley, Nisbett, \& Valins 1971; Weiner, 1979), people perceive the effort as under one's own control. In essence, previous research demonstrated that the effort is considered important and rewarded in the attribution of successes and failures (Weiner and Kukla, 1970; Weiner, $1979 ; 1985 ; 1986 ; 1995)$. Therefore, in case of difference in the level of effort, the findings are consistent with the existing literature.

Results also revealed the same pattern for the ability contribution. In other words, participants applied 
equity principles when allocating rewards in the ability condition, similar to effort condition. This finding is inconsistent with the previous studies finding that when the contribution is in relation to talent, people are likely to prefer equal distribution (Lamm and Kayser, 1978; Kayser and Lamm, 1980; Lamm, Kayser, Schanz, 1983; Şahin, 2003).

In summary, this study revealed that there are similar processes on the basis of fairness perceptions of the reward and cost distributions; people do not display ingroup favoritism when allocating the negative outcomes; when an in-group member contributes more through her/ his talent, the reward is allocated based on the equity principle, whereas it is an out-group member, the reward is allocated based on the equality principle, which is the only condition demonstrating in-group favoritism. 